\title{
Hedonismo e consumo: o papel do especialista da área do vinho como mediador de experiências
}

\author{
Carla Teixeira*
}

\begin{abstract}
Resumo
Inscrevendo-se este trabalho no âmbito conjugado da Teoria do Texto e do Interacionismo Sociodiscursivo, defender-se-á que o domínio de uma prática discursiva por parte do produtor textual se reflete no texto. Este ponto de vista será exemplificado a partir da análise de um corpus de géneros textuais que combinam a atividade de produção e de comercialização do vinho com a atividade jornalística, em particular, no género recensão crítica sobre o vinho. Atendendo a que o conjunto de textos observado se integra no que se chama de imprensa "de serviços" moderna que participa da sociedade de hiperconsumo e tendo como dispositivo de análise os tipos de discurso, serão analisadas as representações que o jornalista especialista constrói de si (figuração interna do agir) e do seu interlocutor, o leitor-consumidor (figuração externa do agir), posteriormente contrastadas com outros textos jornalísticos sobre o vinho. Os dados demonstrarão que o conhecimento sobre o vinho do especialista influencia diretamente a experiência hedonista que é construída no texto, pelo que só o agir deste sujeito é que pode mediar uma experiência qualificada.

Palavras-chave: Teoria do texto. Interacionismo Sociodiscursivo. Agir. Especialista.
\end{abstract}

Muitas pessoas trabalham para a Harley-Davidson. A boa notícia é que... elas não são tolas para acreditar que "fabricam motocicletas." Se não são "motocicletas", então o que é?

Que tal, "experiências"?

Um Grande da Harley resumiu isso da seguinte forma: "Nós vendemos a capacidade de um contabilista de 43 anos vestir-se com couro preto, atravessar pequenas cidades e ter pessoas com receio dele."

Como?

É a experiência, estúpido! (...)

Pense nisso. A Harley-Davidson não vende motocicletas. A Starbucks não vende café. O Club Med não vende férias. E a Guiness não vende cervejas.

Tom Peters,

Reinventar o Mundo!, p. 116-118

Centro de Linguística da Universidade Nova de Lisboa. 
Introdução ${ }^{1}$

O estudo das relações que os seres humanos estabelecem em sociedade é complexo e depende da análise tanto das ações sociais como das interações linguísticas. Essas ações e interações estão representadas nos géneros textuais e nos textos e retratam, por sua vez, as mudanças que se dão em sociedade.

Realizado no âmbito de uma bolsa de investigação de doutoramento, ${ }^{2}$ este trabalho situa-se no campo da Teoria do Texto, sob a perspetiva teórica do Interacionismo Sociodiscursivo (doravante, ISD). É intenção do estudo demonstrar que:

- os textos são representantes empíricos das dinâmicas sociais, pelo que, numa ótica combinada de estudos linguísticos e sociais, os textos analisados da área do vinho revelam uma dinâmica de consumo e de indução de experiências hedonistas;

- a conjugação da área do vinho com outras atividades sociais e os produtores textuais, na figura do especialista e do não especialista, determinam o tipo ou qualidade de experiências que propõem. Na verdade, como anuncia a epígrafe, a valorização da experiência é transversal às várias atividades económicas da sociedade contemporânea, cuja formulação nos textos da área do vinho importa verificar.

\section{Quadro teórico e metodologia de análise}

A presente investigação situa-se no domínio científico linguístico da Teoria do Texto conjugada com o enquadramento teórico do ISD.

Tendo o estudo do texto suscitado interesse no campo linguístico, os projetos das análises transfrásicas, das gramáticas textuais e das diversas linguísticas do texto ilustram a progressiva atenção e o amadurecimento da problematização do texto como objeto de análise linguístico. Assim, a Teoria do Texto surge como uma abordagem aprofundada do desenvolvimento das relações entre os diversos

$1 \mathrm{O}$ presente trabalho foi escrito ao abrigo do Acordo Ortográfico em vigor em Portugal, contudo os exemplos que constam no mesmo são anteriores à sua aprovação. Foi financiado por Fundos Nacionais através da FCT - Fundação para a Ciência e Tecnologia (Portugal), no âmbito do projeto Pest-OE/LIN/ UID/LIN/03213/2013.

2 A tese de doutoramento foi realizada no domínio de especialidade Linguística do Texto e do Discurso, tendo sido orientada pela Professora Doutora Maria Antónia Coutinho e coorientada pela Professora Doutora Clara Nunes Correia, da Faculdade de Ciências Sociais e Humanas - Universidade Nova de Lisboa, Portugal. 
elementos que intervêm na produção textual, assumindo uma lógica de análise descendente por meio do reconhecimento da atividade social à qual o texto pertence, do género textual adotado e do texto como a materialização de uma mensagem formulada em função das influências sociais e genéricas textuais. Esse ponto de vista é exposto por Coutinho do seguinte modo:

Trata-se, com efeito, de tomar em consideração, em primeiro lugar, a atividade social em que o texto surge - bem como o género de texto selecionado, de entre os géneros em uso nessa mesma atividade; a compreensão das finalidades associadas à atividade em causa e o reconhecimento das características próprias do género em uso condicionarão, em última análise, muitas das escolhas linguísticas (realizadas de forma mais ou menos consciente e explícita). (COUTINHO, 2012, p. 31).

Como se demonstrará, a Teoria do Texto e o ISD partilham dos mesmos princípios teórico-epistemológicos e metodológicos, o que justifica este estudo combinado de géneros textuais produzidos a partir de uma atividade económica que constitui uma mesma prática discursiva.

O ISD é, pois, um enquadramento teórico-metodológico orientado pelos princípios epistemológicos do Interacionismo Social, que participa, por um lado, no desenvolvimento de uma ciência do humano e, por outro lado, reflete sobre o desenvolvimento do ser humano em sociedade, a partir das colaborações de áreas que partilham dessa motivação, como é o caso da Psicologia, Sociologia e Linguística.

Visto que "as propriedades específicas das condutas humanas são o resultado de um processo histórico de socialização, possibilitado especialmente pela emergência e pelo desenvolvimento dos instrumentos semióticos" (BRONCKART, 2003, p. 21), o ISD entende que as aquisições sociocognitivas dos indivíduos decorrem do processo evolutivo dos seres humanos, por meio da libertação das restrições biológicas e comportamentais.

Considerando o exposto, destacam-se duas linhas de estudo do ISD relacionadas com os processos filogenético e ontogenético que comprovam a apropriação das propriedades sociossemióticas por parte dos seres humanos, assinalando uma transformação da identidade e da consciência humanas como promotoras da (re) construção do universo social: em primeiro lugar, o estudo das condições nas quais se desenvolvem formas particulares de organização social humana e formas 
de interação de caráter semiótico, e de como estas últimas podem influenciar o desenvolvimento das primeiras; e, em segundo lugar, o estudo das caraterísticas estruturais e funcionais das organizações sociais e das formas de interação semiótica.

Sublinha-se que é a capacidade reflexiva intrínseca ao uso da linguagem que permite aos indivíduos apropriar-se do verbal e do seu potencial de ação, o que está patente nos textos. Esse princípio é nomeado como o primado da dimensão praxeológica da linguagem, cuja formulação está igualmente presente nos manuscritos de Saussure, como se pode verificar de seguida, na qual o autor explica que o valor da forma linguística depende da intenção comunicativa atribuída pelo sujeito:

Avant tout on ne doit pas se départir de ce principe que la valeur d'une forme est tout entière dans le texte où on la puise, c'est-à-dire dans l'ensemble des circonstances morphologiques, phonétiques orthographiques, qui l'entourent et l'éclairent. (SAUSSURE, 1994/1922, p. 514³ apud BRONCKART, 2009, p. 19).

Sendo a intenção comunicativa influenciada pela atividade social, preconizase uma abordagem de análise descendente, a partir da noção de dialogismo de Jakubinski reformulada por Volochinov, ${ }^{4}$ tida como fundamental a toda e qualquer produção verbal: independentemente do caráter dialogal ou monológico das realizações de linguagem concretas, o dialogismo é compreendido por Volochinov como propriedade intrínseca de qualquer interação verbal (BRONCKART, 2010, p. 157-8).

Baseando-se nesses pressupostos, Volochinov implementa um programa metodológico de lógica descendente: analisando as propriedades linguísticas na interação verbal e dos enunciados presentes nos textos (BOTA; BRONCKART, 2007, p. 82), a produção verbal é considerada em contexto e integrada nas formas de organização coletiva da sociedade.

3 SAUSSURE, Ferdinand de. Mémoire sur le système primitif des voyelles dans les langues indoeuropéennes. In: BALLY, Charles; Gautier, Léopold (Ed.). Recueil des publications scientifiques de Ferdinand de Saussure. Genève: Sonor, 1992.

4 VOLOCHINOV, Valentin N. Le marxisme et la philosophie du langage. Paris, Minuit, 1977 [1929]; VOLOCHINOV, Valentin N. Le discours dans la vie et le discours en poésie. In: TODOROV, Tzvetan (Ed.). Mikhaïl Bakhtine: le principe dialogique. Paris: Seuil, p. 181-215, 1981a [1926]; VOLOCHINOV, Valentin N. La structure de l'énoncé. In: TODOROV, Tzvetan (Ed.). Mikhaïl Bakhtine: le principe dialogique. Paris: Seuil, p. 287-316, 1981b [1930]. 
Deste modo, e em consonância com princípios já apresentados, no decurso desta investigação foram igualmente adotadas as seguintes noções (expostas sinteticamente):

- atividade discursiva: ao contrário do sentido demasiado restrito de atividade económica do qual também se fará uso pontualmente, a atividade discursiva refere-se ao conjunto das manifestações da linguagem dos indivíduos realizadas em situações concretas (BRONCKART, 2004, p. 102);

- género textual: o modelo de texto é compreendido numa atividade de linguagem à qual corresponde uma ação de linguagem que "reúne e integra os parâmetros do contex to de produção e conteúdo temático, tais como um determinado agente os mobiliza, quando empreende uma ação verbal.” (BRONCKART, 2003, p. 99). Além de um género ser caraterizado atendendo à sua localização temporal, geográfica e social, essa noção afigura-se extremamente relevante já que todas as produções verbais são construídas tendo em vista os géneros textuais que circulam em sociedade, pelo que o género textual detém um papel mediador entre o individual e o coletivo, como lembra Rastier (2001, p. 272-3): "le genre partage tout à la fois le caractère public de l'action individuelle socialisée et la norme sociale où elle prend place".

- texto: tido como uma unidade comunicativa de nível superior, relativamente às outras unidades linguísticas que o compõem, "designa toda a unidade de produção de linguagem que veicula uma mensagem linguisticamente organizada e que tende a produzir um efeito de coerência sobre o destinatário" (BRONCKART, 2003, p. 71).

A atividade discursiva, o género textual e o texto representam patamares de análise linguística que serão mobilizados para o estudo do agir humano, ou seja, a observação das unidades que caraterizam o fluxo do agir no ser humano, o único organismo dotado de capacidades mentais e comportamentais.

$\mathrm{O}$ foco sociointeracionista do agir inscreve-se, então, numa reflexão teórico-prática do desenvolvimento do potencial intrínseco do profissional, perspetivando o trabalho como uma forma de organização humana, também designado de agir-referente. Para uma análise linguística do agir, esta fundar-se-á na arquitetura interna dos textos, em particular no subnível dos mecanismos de responsabilização enunciativa (BRONCKART, 2003, p. 319-336), que contribui para clarificar quais as fontes das avaliações (julgamentos, opiniões, sentimentos) presentes nos textos e sobre o que o produtor textual acerca do conteúdo temático. 
Recorrer-se-á, igualmente, aos tipos de discurso (BRONCKART, 2003, p. 137216), configurações linguísticas identificáveis nos textos que resultam de quatro mundos discursivos ou arquétipos psicológicos. Essas semiotizações decorrentes de uma língua natural - discurso interativo, discurso teórico, relato interativo, narração - apresentam propriedades morfossintáticas e semânticas estáveis em função do eixo da temporalidade - em conjunção com o momento da enunciação e compondo a ordem do expor (discurso interativo, discurso teórico) ou em disjunção com o momento da enunciação e formando a ordem do narrar (relato interativo, narração) - e em função do eixo da atorialidade - implicação enunciativa do sujeito (discurso interativo, relato interativo) ou autonomia enunciativa do sujeito (discurso teórico, narração).

\section{A sociedade de hiperconsumo}

De acordo com Lipovetsky (2007), o século XX evidencia mudanças graduais na sociedade de consumo ocidental comprovadas em três períodos: (i) no início de novecentos, um primeiro momento de democratização e de facilidade de acesso aos bens de consumo, devido ao desenvolvimento dos meios de transporte e das técnicas de produção em série; (ii) após a $\mathrm{II}^{\mathrm{a}}$ Guerra Mundial, um segundo momento de valorização dos bens que proporcionam bem-estar e promovem o status quo; (iii) a partir dos anos 70 e 80 do século $\mathrm{XX}$, um terceiro momento, que vigora até aos nossos dias, no qual o consumo está orientado para a satisfação pessoal, sendo o hedonismo o fim a atingir enquanto experiência do indivíduo.

De facto, a sociedade contemporânea está tão orientada para a busca do prazer por meio da aquisição de bens que o mesmo autor apelida-a de sociedade de hiperconsumo:

Não encontro termo mais adequado que o de «hiperconsumo» para definir uma época em que os gastos já não têm por motor o desafio, a diferença, os confrontos simbólicos entre os homens. Quando as lutas de concorrência já não são a pedra angular da aquisição de produtos, começa a civilização do hiperconsumo, esse império sobre o qual brilha continuamente o sol do mercado e do individualismo. (LIPOVETSKY, 2007, p. 37).

Além de singular, a experiência do hiperconsumo designa a realização do desejo do indivíduo que se sobrepõe a qualquer outro tipo de motivação, 
predominando o que Baudrillard (2008, p. 95) chama de fun morality. Promovida por um "marketing sensorial ou experiencial" (LIPOVETSKY, 2007, p. 39) que glorifica os sentimentos de felicidade e de prazer, a aquisição emocional dos bens oferece uma nova vivência do produto de mercado. Efetivamente, a gratificação emocional do indivíduo através da fruição do produto é estimulada pelas atividades económicas como o comprova Lipovetsky:

O capitalismo de consumo não nasceu automaticamente de técnicas industriais capazes de produzir em grande série produtos estandardizados, mas foi também uma construção cultural e social que exigiu a «educação» dos consumidores e necessitou do espírito visionário de empresários criativos, a «mão visível dos gestores»." (LIPOVETSKY, 2007, p. 24-25).

No âmbito dessa dinâmica conjuntural, as atividades económicas procuraram outros meios de divulgação dos produtos e encontraram uma nova visibilidade em géneros jornalísticos que, à semelhança dos géneros textuais publicitários, tratam de bens de consumo ou de serviços.

\section{Uma imprensa "de serviços" moderna}

Os géneros textuais ${ }^{5}$ produzidos na esfera da atividade jornalística e da atividade publicitária apresentam afinidades, pois estão historicamente relacionados a partir de uma vertente informativa e, posteriormente, de uma vertente de comentário: essa ligação dá-se a partir de um primeiro género primitivo, a notícia curta, que remonta ao século XVII (GROSSE, 2001, p. 17-19) ${ }^{6}$ e cuja evolução posterior

5 Neste trabalho, apesar de teórica e metodologicamente se adotar a noção de género textual, far-se-á uso de contributos de autores que optam pela noção de género de discurso. Sucintamente, a adoção desta última noção valoriza a associação entre discurso e texto, o que evidencia as caraterísticas comuns entre os textos, chamadas ares de família; no entanto, os géneros discursivos entendem os géneros como pertencentes a domínios sociais e com práticas discursivas distintas, ao contrário da noção adotada de género textual, que identifica uma mesma atividade, na origem ou como integrante do contexto de produção.

6 Os dados de Grosse remetem para a investigação diacrónica sobre os géneros jornalísticos de uma gazeta italiana fundada no século XVIII, a Gazeta de Mântua, de Anja Hrbek, Vier Jahrhunderte Zeitungsgeschichte in Oberitalien. Text-, sprach- und allgemeingeschichtliche Entwicklungen in der "Gazzetta di Mantova" und vergleichbaren Zeitungen, 1995. No presente trabalho, assume-se que há modelos textuais com afinidades culturais em termos de civilização europeia, que, de um ponto de vista cronológico, deverão ser considerados contemporâneos, com processos de formação semelhantes, cujas particularidades decorrem dos momentos históricos específicos. Consequentemente, o aparecimento atestado de um género pressupõe um acontecimento semelhante noutros países europeus. Grosse cita igualmente o trabalho de Ulrich Püschel, Raisonnement und Schulrhetorik im öffentlichen Diskurs. 
origina outros textos jornalísticos nos quais a informação se destaca a par de elogios.

Pode dizer-se que este terá sido o início do anúncio publicitário, cujo rápido desenvolvimento se deu na segunda metade do século XIX devido à industrialização da produção das mercadorias, proporcionando a independência desses textos face aos textos jornalísticos. Embora esses textos publicitários representem uma extensão do elogio praticado na notícia, presumem, igualmente, uma independência dos mesmos face à notícia, o que se verifica na ainda extensa componente escrita, em comparação com os anúncios de hoje, à qual, por esta altura, que se lhes associam os elementos verbais e os slogans (GROSSE, 2001, p. 18).

Ainda que seja possível reconstituir o parentesco entre os géneros publicitários e os géneros publicitários ao longo dos tempos, no momento presente, atendendo às singularidades de algumas publicações, é de considerar quando os textos jornalísticos sobre produtos e serviços são escritos no contexto de uma imprensa especializada ou não.

É Grosse que aponta a existência de uma imprensa "de serviços" moderna presente nos suplementos ilustrados ou nas revistas semanais, frequentemente editadas próximo do fim de semana, e que compreendem testes sobre problemas psicológicos, horóscopos, textos de conselhos sobre vestuário, restauração, viagens, entre outros assuntos, referindo explicitamente informações (nome da marca, morada, telefone, preço, ...) sobre o produto ou o serviço divulgado. O mesmo autor utiliza ainda a expressão "publicité rédactionnelle" (GROSSE, 2001, p. 27) para designar a divulgação de um produto ou de um serviço numa publicação jornalística, num texto escrito por um jornalista.

Considerando a existência de dois posicionamentos enunciativos inerentes aos géneros da atividade jornalística, Adam (1997, p. 8, a partir de BROUCKER ${ }^{7}$ ) diferencia géneros de informação e géneros de comentário, com base em três critérios linguísticos: (i) o critério semântico (relacionado com o sujeito); (ii) o critério argumentativo e pragmático (que se divide em ponto de vista informativo, respondendo às questões quem?, o quê?, onde?, quando?, e em ponto de vista explicativo, respondendo a como? e porquê?); e o critério enunciativo (a posição do jornalista relativamente ao discurso e às fontes). 
A aplicação dos critérios mencionados permite identificar os géneros de informação, os géneros tradicionais e tipicamente jornalísticos, como, por exemplo, a notícia, a reportagem, a notícia de investigação e a entrevista. Esses géneros surgiram com as folhas avulsas de imprensa, que, na época do pré-capitalismo italiano, satisfazem a curiosidade de negociantes, banqueiros internacionais, príncipes e comitivas por notícias sobre os conflitos ou a conjuntura política que obrigassem a um reajustamento das estratégias mercantis.

Os chamados géneros de comentário integram os comentários propriamente ditos de vários tipos, bem como o editorial, e têm origem nos ideais revolucionários franceses que promovem uma imprensa de debate a par da informação. Como procedente do comentário, na sociedade de hiperconsumo de hoje, o conselho foise tornando cada vez mais frequente, incentivando o leitor e consumidor à compra, em detrimento do artigo de opinião, que suscita uma atitude mais introspetiva (GROSSE, 2001, p. 26-27).

Sendo a sociedade do consumo caraterizada por uma constante reinvenção das necessidades do consumidor e por uma notável variedade de bens de consumo, constatou-se que a realidade da atividade portuguesa de produção e comercialização do vinho conheceu recentemente um desenvolvimento técnico exponencial, que permitiu aumentar a quantidade e a qualidade de fabrico (YON, 2003). Em Portugal, a atividade de produção e de comercialização do vinho beneficiou de melhorias técnicas na produção do vinho, com grande impacto qualitativo, o que foi acompanhado por uma renovação da imagem das marcas e dos hábitos de consumo da área do vinho. Também se verificou que, além das mencionadas inovações, a mesma atividade do vinho conseguiu dinamizar um interesse generalizado sobre a área através da criação de cursos de iniciação à degustação de vinhos com bastante afluência, bem como se deu um aumento do interesse mediático dos leitores e consumidores o que foi visível na imprensa escrita.

\section{Géneros e textos indutores da ação}

Nessa dinâmica contemporânea de consumo, há ainda uma outra questão a problematizar e que engloba tanto os géneros publicitários como os géneros jornalísticos: como é que um texto orienta o consumidor na compra de um produto?

Qualquer texto de índole publicitária dirige-se a um consumidor cooperante que 
aceita tacitamente uma dimensão persuasiva presente no texto, o que demonstra uma harmonia entre a dimensão ilocutória (o(s) ato(s) ilocutório(s) expresso(s) no texto) e a dimensão perlocutória (o efeito do ato ilocutório). Esse entendimento de Adam e Bonhomme (2007) está sintetizado no quadro 1, que se segue.

QUADRO 1 - A esquematização da estrutura pragmática do discurso publicitário

\begin{tabular}{|l|ccc|}
\hline $\begin{array}{c}\text { Ação de } \\
\text { língua }\end{array}$ & $\begin{array}{c}\text { Produzir uma } \\
\text { mensagem }\end{array}$ & $\begin{array}{c}\text { com uma força } \\
\text { persuasiva }\end{array}$ & $\begin{array}{c}\text { visando a compra } \\
\text { do produto }\end{array}$ \\
$\begin{array}{c}\text { Dimensão } \\
\text { pragmática }\end{array}$ & $\begin{array}{c}\text { Ato } \\
\text { LOCUTÓRIO }\end{array}$ & $\begin{array}{c}\text { Força } \\
\text { constativa (explícito) }\end{array}$ & $\begin{array}{c}\text { Efeito } \\
\text { PERLOCUTÓRIO } \\
\text { fazer crer }\end{array}$ \\
& & diretiva (+ ou - implícito) & fazer fazer \\
\hline
\end{tabular}

FONTE: Traduzido de ADAM; BONHOMME, 2007, p. 25.

A leitura do quadro indica que Adam e Bonhomme consideram os atos ilocutórios constativo e diretivo complementares, o que é sintetizado pelos autores do seguinte modo: "L'acte illocutoire dominant de la plupart des publicités est explicitement constatif et implicitement directif" (ADAM; BONHOMME, 2007, p. 25). De facto, o ato diretivo pode ser marcado por formas verbais com menor valor injuntivo, como em enunciados equivalentes a "Aconselha-se a compra deste produto" (por oposição a enunciados do tipo "Compre", "Adquira" com forte valor injuntivo); entenda-se, então, a opção por uma formulação implícita e, consequentemente, atenuada pela apresentação do produto enunciada no ato constativo em "Este produto é (muito) bom", visto que o objetivo final de qualquer texto publicitário é expor comercial e positivamente o bem de consumo que anuncia, para que essa mesma exposição conduza o consumidor à aquisição desse bem. Dessa forma, no plano perlocutório, a compra decorre da estratégia publicitária resultante dos referidos atos ilocutórios concertados: o ato constativo relaciona-se com o valor do bem e o ato diretivo conduz à sua compra.

Contudo, e evocando outros estudos de Adam, os géneros podem ser também observados em função do estudo do agir a que o autor chamou de "géneros de incitação à ação", uma família de textos com uma ação discursiva integrada no dire de faire: "il s'agit de faire-faire quelque chose à quelqu'un, de l'y inciter plus ou moins fortement surtout de lui garantir la vérité des informations fournies" 
(ADAM, 2001, p. 21). Segundo o autor, esses géneros surgem no final do século XVII, no contexto da tradição judaico-cristã, como a versão laica de preceitos ou conselhos religiosos que tratam a vida mundana de um ponto de vista moral, orientando as pessoas com sabedoria, o que justifica que se sublinhe o valor ilocutório diretivo dos mesmos textos que cobrem o campo lexical do "conselho", visto que "conseiller, c'est indiquer à quelqu'un ce qu'il doit faire ou ne pas faire et ce guidage va de suggérer, recommander, et proposer à presser, inciter, pousser (à), en passant par avertir, aviser, conduire, persuader, convaincre, diriger " (ADAM, 2011, p. 233).

No entanto, a noção de géneros de incitação à ação foi objeto de reformulações. De acordo com Adam $(2001 ; 2011)$, os géneros de incitação à ação contemplam dois conjuntos: (i) os géneros de incitação à ação, propriamente ditos, e que abrangem produções textuais tão díspares como, por exemplo, enunciados injuntivos, textos legais, requerimentos e regulamentos, ou regras de jogos e didascálias teatrais (instruções cenográficas ou de encenação); (ii) os géneros de procedimentos (em francês, genres procéduraux), como uma especificidade dos géneros de incitação à ação, referindo os textos injuntivos, os textos de procedimentos e também diferentes formas de conselhos, para cuja análise é essencial o foco nos planos de texto, organizados em "description-liste pour ingrédients des recettes ou éléments épars des notices; description d'actions pour la suite d'actes à accomplir" (ADAM, 2011, p. 226).

Esse procedimento metodológico-descritivo contribui para a distinção entre os géneros de incitação à ação per se e os géneros de procedimentos, pois os primeiros pertencem a uma categoria mais vasta, contemplando diferentes domínios discursivos e com a finalidade prática de incentivar alguém a fazer algo, seja uma tarefa seja uma macroação com base em informações previamente fornecidas e cuja veracidade está assegurada pelo estatuto de especialista do enunciador. Nesses géneros, há igualmente uma unidade configuracional entre o tema e o ato do discurso, assim como uma homogeneidade pragmático-semântica e redatovisual (scripto-visuelle) (ADAM, 2001, p. 21; ADAM, 2011, p. 227).

Os segundos géneros, os de procedimentos, são textos que salientam o "fazer", pondo num plano secundário a orientação da ação, o que se entende por injunção-instrução ou conselho. Além disso, de acordo com Adam (2011, p. 229), "les textes procéduraux ou programmateurs n'engagent aucune réflexion sur l'agir humain et sur l'inscription de l'homme dans le temps". 
Como já foi referido, a ação dos sujeitos em sociedade ou o agir humano é uma questão essencial para o ISD. De momento, e apesar de algumas diferenças entre a noção de agir de Adam e a noção sociointeracionista, é de reter a importância da reflexão sobre o próprio agir do sujeito para qualificar a experiência de consumo, como se provará no decurso da análise.

\section{Descrição do corpus}

A análise a realizar refere-se a um conjunto de trinta textos em circulação, recolhidos entre 2006 e 2011 pertencentes ao género textual recensão crítica sobre o vinho (publicação especializada e publicação não especializada) e produzidos na esfera da atividade de produção e de comercialização do vinho combinada com a atividade jornalística. Além de o vinho ser o objeto temático comum aos textos do corpus, considerar-se-á a atividade do vinho como a atividade predominante, na medida em que é esta que desencadeia o processo de produção textual e, como se verá, é o conhecimento ou domínio da mesma por parte do produtor textual que garante a qualidade das recomendações e das experiências. Os dados aferidos a partir da análise do corpus serão posteriormente confrontados com um conjunto de outros textos jornalísticos. ${ }^{8}$

Os géneros textuais escolhidos justificam-se pelo interesse em caraterizar a atividade de produção e comercialização do vinho através de objetos empíricos diversificados nos quais o vinho fosse uma temática presente, mas que pudesse apresentar diferentes tratamentos do conteúdo temático, o que se verifica na centralidade do tema vinho nas recensões críticas sobre o vinho, de vários autores e para o público em geral ou especializado.

Todos os textos encontram-se assinados, pelo que é de considerar uma primeira instância enunciativa, o autor, como aquele que se responsabiliza pela escolha do género textual e respetivo conteúdo temático, bem como por outros recursos linguísticos (léxico, morfossintaxe, tipos de discurso, tipos de planificação). Em particular, o autor de uma recensão crítica sobre o vinho é uma figura que profissionalmente é reconhecida no meio jornalístico e/ou do vinho, pelo que os seus textos, enquadrando-se no espírito da imprensa "de serviços" moderna, têm as recomendações caucionadas pela assinatura do especialista. Com efeito, esse

8 Para pormenores fundamentados sobre a metodologia de recolha dos textos e organização da investigação, cf. Santos (2014, p. 102-9). 
género textual oferece recomendações sobre vinhos a consumir ou locais a visitar do universo do vinho. De um ponto de vista da ação humana, a recensão crítica pretende orientar as escolhas do consumidor, prévias ao ato da compra.

Os outros textos jornalísticos são um grupo de textos à parte, que surgem na sequência da recolha inicial dos textos que uma análise mais aprofundada comprovou não poderem ser classificados como recensão crítica sobre o vinho. Porém, para um estudo mais detalhado da sociedade de hiperconsumo, da atividade do vinho e do agir humano optou-se pela sua manutenção na investigação. A lista dos exemplares selecionados para análise encontra-se no Anexo A.

\section{Análise de textos}

Como foi afirmado na introdução, o estudo das relações humanas é alcançado através da análise das ações sociais e das interações linguísticas. Na perspetiva sociointeracionista, a observação do social deverá ter por base uma fundamentação linguística. Desse modo, para dar conta da forma como é construída uma experiência hedonista na área do vinho no corpus, a análise linguística focar-se-á na relação entre a componente enunciativa e os pontos de vista apresentados sobre a temática do vinho, fazendo-se dos tipos de discurso o dispositivo de análise do agir humano, especialmente das formas e construções linguísticas caraterísticas dos discursos observados.

Sendo a atividade do vinho tipicamente técnica, como é que o leitor ou consumidor, que não é especialista, é orientado para uma compra? Como é que o leitor ou consumidor é persuadido do valor singular do produto vinho?

A convicção que o leitor-consumidor poderá ter de que o texto lido é idóneo decorre do equilíbrio entre dois elementos: a representação que o jornalista especialista da área dos vinhos constrói de si mesmo e a representação que o jornalista constrói do interlocutor. Posto isto, a análise focar-se-á na atorialidade ou no modo de "desempenho de especialista da área do vinho que se revela por meio do registo escrito da própria experiência e/ou do conhecimento sobre o bem de consumo vinho, e que poderá ser empregue para induzir a experiência futura neste campo no leitor do texto" (SANTOS, 2014, p. 157).

Numa seleção de formas verbais do corpus do género recensão crítica enológica (publicação especializada), foi possível verificar que sobressaem formas linguísticas que indicam a presença do locutor e do interlocutor. 
No que diz respeito à representação que o jornalista especialista constrói de si, no género recensão crítica enológica, foram aferidas formas verbais de primeira pessoa do singular que reproduzem o ponto de vista do produtor textual e, em termos de desempenho atorial no âmbito da atividade de produção e de comercialização do vinho, o ponto de vista do jornalista especialista no vinho. Nesse sentido, o sujeito locutor manifesta vários tipos de interesse inerentes à experiência do vinho, construindo uma referência intratextual do vinho, como se pode verificar pelos seguintes exemplos do quadro 2 :

QUADRO 2 - A apresentação do ponto de vista do jornalista

\begin{tabular}{|c|c|}
\hline $\begin{array}{l}\text { O jornalista apresenta o seu ponto de vista } \\
\text { quando ... }\end{array}$ & Exemplo \\
\hline $\begin{array}{l}\text { - evidencia o conhecimento de histórias nas } \\
\text { quais o vinho assume um papel relevante }\end{array}$ & 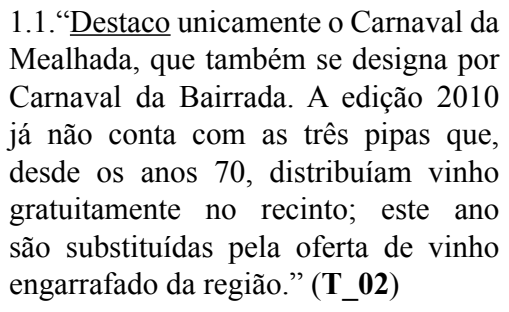 \\
\hline $\begin{array}{l}\text { - recomenda locais de produção de vinho } \\
\text { pelo seu valor turístico, com base na sua } \\
\text { própria experiência }\end{array}$ & $\begin{array}{l}\text { 1.2. "Proponho que ofereça um pouco } \\
\text { da calma do enoturismo da Quinta } \\
\text { do Vallado, uma quinta histórica no } \\
\text { vale do rio Corgo, aos pés da Régua } \\
\text { e do Douro, rio de vinho. Pertence a } \\
\text { descendentes de D. Antónia Adelaide } \\
\text { Ferreira, a Ferreirinha. A vista é única } \\
\text { no mundo (pode reservar em } \underline{w w} \text {. } \\
\text { quintadovallado.com)." (T_03) }\end{array}$ \\
\hline $\begin{array}{l}\text { - realça o valor de um vinho com base nas } \\
\text { suas caraterísticas idiossincráticas }\end{array}$ & $\begin{array}{l}\text { 1.3. "Destaco um branco enraizado nas } \\
\text { areias de Fernando Pó, entre Palmela } \\
\text { e Pegões, elaborado com Sauvignon } \\
\text { Blanc e Verdelho, duas castas pouco } \\
\text { usuais em terras de Moscatel e Fernão } \\
\text { Pires." (T_03) }\end{array}$ \\
\hline
\end{tabular}


- opina sobre questões estéticas de publicidade com implicações comerciais
1.4. "Já agora, aproveitando o embalo, sugiro à Adega Cooperativa de Borba que repense os seus rótulos, que primam pelo mau gosto (mas podem e devem deixar o do cortiça, que é um marco histórico e tem piada!).” (T_15); "Garanto que aliar uma imagem agradável a vinhos de qualidade chamará ainda mais a atenção do consumidor e só irá beneficiar o negócio[.]" (T_15)

De um modo geral, os segmentos indicados exemplificam momentos de discurso interativo que, ao fazer uso do presente do indicativo, ${ }^{9}$ do ponto de vista da temporalidade, mostram o locutor reportar a um momento da enunciação temporalmente alargado, identificada pelo uso de conetores temporais ("A edição 2010", T_02) e ao momento específico da enunciação, continuamente reatualizado pelo leitor em cada leitura (“destaco", T_02 e T_03; "proponho", T_03) ou com implicações para o futuro desenrolar da atividade ("garanto", T_15).

A atorialidade do sujeito surge, igualmente, construída a partir de formas verbais com pronomes pessoais oblíquos não reflexivos que apontam para vivências pessoais bem definidas tematicamente na atividade de produção e de comercialização do vinho, maioritariamente ancoradas no presente do indicativo, mas com exemplos pontuais de formas verbais pretéritas.

Marcando a presença da capacidade atorial do sujeito-locutor em refletir sobre o seu desempenho, os seguintes segmentos do quadro 3 com formas verbais e pronomes pessoais oblíquos não reflexivos assinalam: 
QUADRO 3 - A autorreflexão sobre o desempenho do jornalista

\begin{tabular}{|c|c|}
\hline $\begin{array}{l}\text { O jornalista reflete sobre } \text { o } \text { seu } \\
\text { desempenho quando... }\end{array}$ & Exemplo \\
\hline $\begin{array}{l}\text { - o momento da escrita do texto, é marcado } \\
\text { pelo presente do indicativo e reforçado } \\
\text { pelo uso do adverbial temporal "hoje" }\end{array}$ & $\begin{array}{l}\text { 1.6. "Alguns dos nossos conhecidos } \\
\text { petiscos mais conhecidos são inimigos } \\
\text { do vinho. Refiro-me (hoje) ao escabeche, } \\
\text { principalmente se for temperado com } \\
\text { algum desses vinagres de péssima } \\
\text { qualidade que abundam no mercado." } \\
\text { (T_10) }\end{array}$ \\
\hline $\begin{array}{l}\text { - reconhece a importância da memória na } \\
\text { produção textual, como base do momento } \\
\text { da escrita definido pelo presente do } \\
\text { indicativo: }\end{array}$ & $\begin{array}{l}\text { 1.7. "Lembro-me de um provador que } \\
\text { estava comigo num concurso em Londres } \\
\text { e num grupo onde se iria provar vinhos do } \\
\text { Porto" (T_11) }\end{array}$ \\
\hline $\begin{array}{l}\text { - expõe a proximidade (ou as relações } \\
\text { que se estabelecem no meio) entre os } \\
\text { produtores de vinho e os jornalistas, } \\
\text { reforçando enunciativamente o ponto de } \\
\text { vista do sujeito locutor que, por sua vez, } \\
\text { é introduzido por um verbo declarativo } \\
\text { (dizer) que aponta para um momento, } \\
\text { entre outros, de interação produtor de } \\
\text { vinhos-jornalista: }\end{array}$ & $\begin{array}{l}\text { 1.8. "No [concurso] de Bruxelas, este ano, } \\
\text { foram cerca de } 6200 \text { amostras, oriundas de } \\
53 \text { países, o que obrigou à presença de } 250 \\
\text { provadores de } 40 \text { nacionalidades. Dizia- } \\
\text { me um produtor que as medalhas ganhas } \\
\text { nestes concursos servem como currículo } \\
\text { do vinho quando o produtor quer exportar, } \\
\text { já que muitas vezes o importador começa } \\
\text { por querer saber o palmarés do vinho e do } \\
\text { produtor." (T_11) }\end{array}$ \\
\hline
\end{tabular}

À semelhança dos segmentos analisados anteriormente, dois dos exemplos deste conjunto são caraterizados pelo uso de formas verbais com pronomes pessoais no presente do indicativo (T_10, T_11), que remetem para uma configuração temporal em conjunção com a enunciação típica do discurso interativo. Esse discurso interativo transita para relato interativo, expressando a descrição de acontecimentos passados por parte do locutor, patente no uso do pretérito imperfeito do indicativo ${ }^{10}$ ("estava", T_11) e do condicional ${ }^{11}$ ("se iria", T_11).

O relato interativo é recuperado novamente pela introdução de um discurso reportado no pretérito imperfeito, seguido de formas verbais no presente do

10 Cf. Oliveira (2003, p. 156-5).

11 Cf. Oliveira (2003, p. 158). 
indicativo ou de estruturas verbais encabeçadas pelo presente do indicativo, no que diz respeito à reincidência dos acontecimentos ("Dizia-me um produtor que as medalhas ganhas nestes concursos servem como currículo do vinho quando o produtor quer exportar, já que muitas vezes o importador começa por querer saber o palmarés do vinho e do produtor.”, T_11). Os segmentos apresentados estão sustentados, então, em situações anteriores ao momento da escrita e que reproduzem vivências do vinho, componentes do plano ontológico do sujeito.

A recensão sobre o vinho pode, igualmente, revelar-se o espaço das escolhas do sujeito-locutor, como resultado dos conhecimentos deste sobre o universo do vinho ("Destes todos, optei por falar sobre o vinho Alfrocheiro, uma casta que é mais representativa no Dão, mas que agora também se encontra com alguma frequência nos encepamentos alentejanos.", T_15).

A construção da referência do vinho poderá depender da verbalização da experiência da prova do vinho, o que se relaciona com o desempenho do jornalista especialista. A prova de vinho, em si, é reforçada pelo uso de expressões e de conetores temporais que denotam a prática na área ("Um vinho só lançado para o mercado em anos excepcionais, que me surpreendeu desde a primeira vez que 0 provei, há alguns anos.", T_16) ou retomada como referência indireta, apelando novamente à experiência profissional ("Especialmente se lhe revelar que, na maioria das vezes, a minha experiência pessoal dita que vinhos elaborados com mais do que uma casta são bem mais interessantes. Neste caso, não podia estar mais bem enganada.", $\mathbf{T}_{-} \mathbf{1 6}$ )

Repete-se, então, nesses segmentos a configuração do relato interativo como indicadora de uma disjunção temporal relativamente ao momento da enunciação, implicada do ponto de vista enunciativo, o que significa que o jornalista recupera experiências passadas, apoiadas nas práticas da prova do vinho, que partilha posteriormente por meio da recensão crítica sobre o vinho.

Com efeito, além dos exemplos observados pertencerem ao género recensão crítica sobre o vinho, em publicações não especializadas, é de comprovar a mesma estratégia de valorização da prática profissional com mecanismos de textualização semelhantes, no mesmo género de texto, em publicações especializadas, em particular, o texto T_19, “Alvarinhos, Porte e ostentação”, de Manuel Silva.

Em T_19, o locutor revela-se na primeira pessoa do plural, possivelmente num exercício em que a responsabilidade enunciativa reflete um know-how partilhado pelos restantes membros do corpo editorial. À semelhança de exemplos 
anteriormente observados, o locutor manifesta-se no presente do indicativo, assumindo totalmente a sua área de especialidade através da prova, como é o reconhecimento e a validação da sua matéria de trabalho no seguinte segmento: "Provamos para si nesta edição 22 Alvarinhos, DOC Vinho Verde e Regionais Minho, da colheita de 2010. Vinhos já disponíveis no mercado por preços justos entre os cinco e os dez euros. Descobrimos alguns tesouros, confirmamos todos os grandes nomes. Alvarinhos vieram para ficar." (T_19) Do mesmo modo, em termos de tipos de discurso, o discurso interativo rege esse segmento no presente do indicativo, ainda que reportando diferentes valores temporais: "provamos" e "descobrimos" apontam para momentos anteriores à situação de enunciação, enquanto "confirmamos" coincide efetivamente com o momento de escrita.

$\mathrm{Na}$ verdade, ainda que, numa primeira parte desta análise, o foco tenha sido a observação das formas verbais de primeira pessoa do singular em recensões críticas enológicas de publicações não especializadas, o recurso à primeira pessoa do plural está igualmente documentado noutras recensões de publicações generalistas, como é patente no seguinte segmento do texto T_06, "A melhor selecção nacional”, de Edgardo Pacheco, em que o sujeito tanto dá conta da sua própria escrita sobre o vinho no passado como no tempo presente: "Ocorreu-nos ir à internet rever o que se disse há um ano sobre o Syrah 2005 - "o melhor vinho do mundo". Desistimos. Falta-nos paciência..."

Relativamente ao segundo elemento, a construção da representação que o jornalista constrói do seu interlocutor desdobra-se em dois momentos: um primeiro momento, que é o da prova de vinho e que é vivido pelo jornalista especialista, e um segundo momento, sequencial, relativamente ao primeiro, em que a mesma prova é mobilizada para o ato da escrita e a este subjaz.

Ainda que o primeiro momento tenha existência independente do segundo, que se pode dar devido ao prazer de degustar um bom vinho, o segundo depende da avaliação realizada pelo especialista. Em suma, os dois momentos, a prova e a escrita, são dirigidos para a transmissão do conhecimento experiencial angariado tendo em vista a figura de não especialista, concretizada, no género recensão crítica sobre o vinho, no leitor.

A transmissão da experiência advém da autoridade instituída do jornalista relativamente ao interlocutor, como foi já analisado, e que é assumida pelo jornalista especialista do vinho na formulação de atos diretivos do seu universo de especialidade. Observem-se os seguintes exemplos: 
QUADRO 4 - A relação de autoridade e o domínio do conhecimento sobre o vinho do jornalista

\begin{tabular}{|c|c|}
\hline $\begin{array}{l}\text { O domínio do conhecimento sobre o } \\
\text { vinho é patente quando o jornalista: }\end{array}$ & Exemplo \\
\hline $\begin{array}{l}\text { - sugere a partilha de experiências } \\
\text { sobre o vinho, cuja avaliação terá como } \\
\text { responsável o próprio jornalista }\end{array}$ & $\begin{array}{l}\text { 2.1. "Em } 2010 \text { proponho um desafio ao } \\
\text { leitor: se alguma estória da sua vida foi } \\
\text { testemunhada ou marcada por uma garrafa } \\
\text { de vinho; se lhe apetecer partilhar esse } \\
\text { momento com o SOL, então envie a sua } \\
\text { (curta) estória e talvez a veja publicada } \\
\text { neste espaço dedicado aos bons néctares. } \\
\text { Como prémio, tomarei a liberdade de } \\
\text { lhe oferecer uma boa garrafa de vinho." } \\
\text { (T_01) }\end{array}$ \\
\hline $\begin{array}{l}\text { - recomenda experiências do vinho, de } \\
\text { âmbito comercial e de âmbito cultural; }\end{array}$ & $\begin{array}{l}\text { 2.2. "APROVEITE para consultar } \\
\text { a nova Rota da Bairrada, em } \underline{w w w} \text {. } \\
\text { rotadabairrada.pt, onde os produtores de } \\
\text { vinho marcam presença e através da qual } \\
\text { o esperam de portas abertas. A abertura } \\
\text { é total na exposição Sangue \& Corpo } \\
\text { Di.Vino - Vinho a Nu, com fotografias } \\
\text { de Diogo Moreira, patente no Museu do } \\
\text { Vinho da Bairrada, na Anadia." (T_02) }\end{array}$ \\
\hline $\begin{array}{l}\text { - aconselha comportamentos socialmente } \\
\text { corretos sobre o consumo do vinho; }\end{array}$ & $\begin{array}{l}\text { 2.3. "DIVIRTA-SE. Beba com moderação. } \\
\text { Se conduzir, por favor, opte por bebidas } \\
\text { não alcoólicas." (T_02) }\end{array}$ \\
\hline \multirow[t]{2}{*}{$\begin{array}{l}\text { - orienta o consumo do vinho, } \\
\text { considerando as boas propriedades do } \\
\text { produto e atendendo à harmonização com } \\
\text { os alimentos, a temperatura indicada ou } \\
\text { indicação do modo de guardar a garrafa ou } \\
\text { de servi-la de imediato. }\end{array}$} & $\begin{array}{l}\text { 2.4. "É UM branco seco, com fruta e } \\
\text { elegância. Tradicional companheiro de } \\
\text { marisco (como ostras, p. e.), mas também } \\
\text { para saladas de peixe com maionese ou } \\
\text { cocktails de marisco. Deve servir bem } \\
\text { fresco }\left(10 / 11^{\circ}\right) \text {./ Dica: beber já mas } \\
\text { guardar algumas garrafas para acompanhar } \\
\text { a evolução em cave." (T_11) }\end{array}$ \\
\hline & $\begin{array}{l}\text { 2.5. "Dica: Muito polivalente, } \underline{\text { pode }} \\
\text { acompanhar qualquer prato que requeira } \\
\text { um branco." (T_13) }\end{array}$ \\
\hline
\end{tabular}


- reconhece a figura do leitor, através do uso das formas pronominais ou das formas verbais no presente do conjuntivo.
2.6. "Provamos para si nesta edição" (T_19)

2.7. "Compre para beber nos meses quentes que se avizinham mas não deixe de "esquecer" umas quantas garrafas para os redescobrir mais tarde..." (T_19)

Ainda que se verifique uma relação de autoridade do especialista do vinho sobre o leitor não especialista, o primeiro assume que o leitor é um interessado em questões do vinho, tratando-o cordialmente e com o distanciamento socialmente recomendado para os desconhecidos em Português Europeu, ao optar pelo uso da terceira pessoa do presente do conjuntivo para marcar o interlocutor ("envie", T_01; “APROVEITE”, “DIVIRTA-SE.”, "beba” , “opte”.”, T_02) ou por expressões marcadas com verbos modais deônticos como dever ou poder em estruturas no presente do indicativo+infinitivo ("Deve servir bem fresco $\left(10 / 11^{\circ}\right)$ ", T_11; "pode acompanhar qualquer prato que requeira um branco.", T_13). De facto, é de assinalar que em todos os exemplos, dada a autoridade do experto, se manifesta um valor deôntico inerente a qualquer tipo de recomendação ou conselho.

Dessa forma, a relação que se estabelece entre locutor/interlocutor ou entre jornalista especialista/leitor procede do texto, enquanto espaço que mimetiza uma cena de interlocução real. Em termos de tipos de discurso, a ligação locutor/ interlocutor está fundada numa atorialidade comprometida, típica do discurso interativo, enunciativamente documentada pelo reconhecimento do outro e, consequentemente, pela formulação de um valor deôntico subjacente ao ato diretivo da compra do vinho.

O leitor do género recensão enológica é, assim, construído como um sujeito que ocupa na atividade de produção e de comercialização do vinho um papel na dinamização comercial do bem de consumo, orientado na compra do vinho e demais atos decorrentes de um consumo adequado ou a quem são recomendados eventos relacionados com o vinho. O texto que lhe é dirigido apresenta um macroato diretivo do tipo Compre! ou Prove!, com recomendações e sugestões que denotam o interesse do especialista sobre como fazê-lo bem. De um ponto de vista atorial, o leitor é um mero agente a quem corresponde uma representação textual de não especialista. 
Em síntese, o jornalista especialista da recensão crítica enológica exprimese usando a primeira pessoa, independentemente de se verificar o singular ou o plural, na descrição da prática profissional, na dimensão de prova do vinho ou na dimensão da escrita jornalística sobre o vinho, em plena posse da sua competência atorial. Por isso, necessitando o leitor de orientação sobre o vinho ou sobre temas relacionados, este é hierarquicamente dependente do jornalista especialista para o usufruto do vinho. A presença dos tipos de discurso circunscreve-se ao discurso teórico, pelo conhecimento manifestado da área do vinho por parte do jornalista especialista, e do discurso interativo pela relação interlocutiva recriada entre o jornalista e o leitor.

Considerando a perspetiva sociointeracionista do estudo do agir em refletir sobre o papel da atividade na qual o desempenho profissional se desenvolve e sobre o modo como a atividade de linguagem constrange ou prescreve a sua prática, esses dados afiguram-se relevantes para a interpretação do agir. Isto é, distinguindo a ação do profissional em ação interna e ação externa (BULEA; BRONCKART, 2012, p. 143), relativamente aos diferentes recursos semiótico-discursivos com consequências ao nível do balanço das auto e heterorrepresentações dos sujeitos, a figuração do agir, é de aprofundar a interpretação dos dados e, consequentemente, da reflexão sobre o agir. Desse modo, verifica-se que a construção da autorrepresentação do jornalista especialista de vinhos sobre si mesmo como conhecedor da área configura uma ação interna, enquanto que a representação construída do leitor-consumidor compõe uma ação externa.

Por oposição, no desenrolar da investigação foram encontrados outros textos sobre o vinho, igualmente assinados, com a mesma macroformulação de atos diretivo e constativo, contudo, sem a presença de formas de primeira pessoa nos textos $\mathbf{T} \_31, \mathbf{T} \_32, \mathbf{T} \_33$ e $\mathbf{T} \_34$ que refiram a prática da prova de vinhos ou a tarefa da escrita, embora esteja presente um nós coletivo que se refere ao produtor textual, assumido em T_35, "fomos falar com quem sabe", ou em T_36, "Em conversa com o i [jornal diário] sobre a estratégia de comercialização...”.

Com efeito, a opinião do especialista é recorrente no mencionado corpus, ainda que não coincida com a do produtor textual como no género recensão crítica sobre o vinho, sendo atribuída: ao produtor, "Henrique Uva" (T_34), ao dono de uma garrafeira "Para Arlindo Santos" (T_35), ou a um representante comercial da sociedade produtora de vinhos "Jaime Antunes, seu gerente" (T_36).

Essas vozes são integradas nos textos com recurso a verbos introdutores de 
discurso, por meio da transcrição direta das palavras, reproduzidas entre aspas, e através da paráfrase, como se pode verificar no quadro 5, sobre a presença do especialista em textos jornalísticos assinados por um não especialista:

QUADRO 5 - A presença do especialista em textos jornalísticos

\begin{tabular}{|c|c|}
\hline $\begin{array}{l}\text { Os tipos de discurso quando o produtor } \\
\text { textual não é o especialista: }\end{array}$ & Exemplos \\
\hline $\begin{array}{l}\text { - em segmentos intercalados de relato } \\
\text { interativo, antecedidos por discurso } \\
\text { teórico, e seguidos de discurso interativo }\end{array}$ & $\begin{array}{l}\text { 3.1. "[discurso teórico] É uma aposta } \\
\text { ousada, mas muito equilibrada em termos } \\
\text { finais, [relato interativo] algo que Henrique } \\
\text { Uva aceita quando diz que "foi algo que } \\
\text { sempre quisemos fazer, mesmo sabendo, } \\
\text { à partida, que iria ser uma tarefa difícil } \\
\text { produzir um vinho de colheita tardia (...) } \\
\text { [discurso interativo] Agora, com o vinho } \\
\text { no mercado temos a certeza de que valeu } \\
\text { a pena todo o tempo que dedicamos a este } \\
\text { projecto"." (T_34) }\end{array}$ \\
\hline $\begin{array}{l}\text { - segmentos de relato interativo, } \\
\text { antecedidos e seguidos de segmentos de } \\
\text { discurso misto interativo-teórico }\end{array}$ & $\begin{array}{l}\text { 3.2. "[discurso misto] A aposta na imagem } \\
\text { é também uma certeza, embora, [relato } \\
\text { interativo] como diz Henrique Uva, } \\
\text { "[discurso misto] as expectativas criadas } \\
\text { por essa imagem têm, efectivamente, } \\
\text { de corresponder e estar em consonância } \\
\text { com o vinho que está dentro da garrafa"." } \\
\text { (T_34) }\end{array}$ \\
\hline $\begin{array}{l}\text { - em segmentos de relato interativo, } \\
\text { precedidos de discurso teórico e seguidos } \\
\text { de discurso misto }\end{array}$ & $\begin{array}{l}\text { 3.3. "[discurso teórico] A inovação surge } \\
\text { assim como uma palavra de ordem da } \\
\text { Herdade da Mingorra, [relato interativo] } \\
\text { como realça o produtor. "[discurso } \\
\text { misto] Se a sustentação da qualidade é } \\
\text { uma preocupação primordial, não deixa } \\
\text { também de ser evidente que tem havido } \\
\text { sempre lugar à inovação. (...)" (T_34) }\end{array}$ \\
\hline
\end{tabular}




\begin{tabular}{|c|c|}
\hline $\begin{array}{l}\text { - em segmentos de relato interativo, } \\
\text { seguidos de discurso interativo }\end{array}$ & $\begin{array}{l}\text { 3.4. "[relato interativo] E esse é um } \\
\text { trilho que o produtor deseja aperfeiçoar. } \\
\text { "[discurso interativo] O nosso colheita } \\
\text { tardia é apenas o primeiro de alguns } \\
\text { produtos da gama M, de Mingorra. No } \\
\text { futuro, esta marca englobará todos os } \\
\text { produtos da linha Mingorra Gourmet. } \\
\text { Estão a ser preparados outros projectos, e } \\
\text { alguns até já estão prontos, que pensamos } \\
\text { serem interessantes e originais também, } \\
\text { mas que apenas gostaríamos de revelar na } \\
\text { altura certa." "(T_34) }\end{array}$ \\
\hline $\begin{array}{l}\text { - em segmentos de relato interativo, } \\
\text { seguidos de discurso teórico }\end{array}$ & $\begin{array}{l}\text { 3.5. "Para Arlindo Santos, dono da } \\
\text { Garrafeira de Campo de Ourique, o termo } \\
\text { "vinho de piscina" não tem qualquer } \\
\text { conotação negativa, antes pelo contrário. } \\
\text { [relato interativo] Usa-se geralmente } \\
\text { para qualificar "[discurso teórico] vinhos } \\
\text { ligados ao Verão, ou seja, vinhos leves, } \\
\text { aromáticos, pouco alcoólicos, com alguma } \\
\text { doçura e que não são gastronómicos".", } \\
\text { "Afinal, lembra Arlindo Santos, é } \\
\text { importante ter em conta que se tratam de } \\
\text { vinhos que podem ser consumidos à beira } \\
\text { da piscina..." no texto (T_35) }\end{array}$ \\
\hline $\begin{array}{l}\text { - em segmentos introdutores de relato } \\
\text { interativo, seguidos de discurso misto }\end{array}$ & $\begin{array}{l}\text { 3.6. "sobre a estratégia de comercialização } \\
\text { da sociedade produtora, [relato interativo] } \\
\text { Jaime Antunes, seu gerente, referiu } \\
\text { que esta "[discurso misto] passa pela } \\
\text { venda directa através da internet (...), } \\
\text { acrescentando que a empresa "está virada } \\
\text { para o mercado externo, França, Holanda } \\
\text { e em negociações com o Brasil." (T_36) }\end{array}$ \\
\hline
\end{tabular}

Nos exemplos mostrados em $\mathbf{T} \_34, \mathbf{T} \_35$ e $\mathbf{T} \_36$, comprova-se que o produtor textual reproduz o ponto de vista de outros, ${ }^{12}$ estratégia associada ao uso do tipo de discurso interativo.

12 A mesma estratégia é utilizada de modo diferente no exemplo que se segue, de uma recensão crítica enológica. É de observar que a reprodução da voz alheia acompanha a descrição das emoções do enólogo José Neiva e revela uma certa solidariedade relativamente à confissão feita, devido ao conhecimento partilhado: "A produção é que vai ser pequena porque muitos bagos não vingaram (chuvas em Maio)", confessou, desalentado mas consciente de que, nestas questões do clima, pouco se pode fazer para contrariar as vicissitudes do tempo." (T_13) 
Tendo em consideração os segmentos do género recensão crítica enológica estudados, do ponto de vista dos tipos de discurso, construir um texto com base na experiência do produtor textual significa ancorar a prática da especialidade no momento presente, o que indica a presença de segmentos de discurso interativo ou de discurso teórico e, consequentemente, uma associação à ordem do expor. A combinação da escrita de especialista com um desempenho profissional coerente aponta para a existência de uma atorialidade divergente daquela manifestada neste último conjunto de textos.

Nos outros textos jornalísticos, quando o produtor textual constrói um texto baseado na experiência alheia, que é a do especialista: o sujeito não especialista que é o produtor textual relata a performance do especialista e funda enunciativamente o relato em experiências concluídas ou descritas no pretérito, o que implica que se esteja perante ocorrências do relato interativo, integradas na ordem do narrar.

$\mathrm{Na}$ verdade, assinalar esse tipo de estratégia indica que o produtor textual habilitado na atividade de produção e de comercialização do vinho contará preferencialmente a sua prática. Do mesmo modo, o produtor textual não especializado recorrerá mais frequentemente à experiência do especialista, porque as experiências que possui são menos significativas e qualificadas.

Esta questão de atorialidade é, ainda, fundamental para discernir quais os textos mais abalizados na recomendação das experiências do vinho ou, por outras palavras, quais os sujeitos mediadores mais competentes entre a atividade do vinho e o consumidor. Em última análise, a atorialidade facilita a distinção entre o género recensão crítica enológica e outros textos da imprensa escrita sobre o vinho.

De modo semelhante, ainda que integrados na imprensa de "serviços" contemporânea, só o género recensão crítica sobre o vinho fornece uma experiência idónea sobre o vinho comparativamente aos textos jornalísticos produzidos por não especialistas, cuja escrita é regida pela lógica de produção de conteúdos.

\section{Considerações finais}

Neste trabalho, procurou estudar-se os textos como objetos empíricos que refletem as interações humanas em sociedade, admitindo que os mesmos textos espelham relações complexas ao nível das atividades sociais, dos géneros textuais e dos indivíduos. Em particular, foram observadas as relações que se estabelecem 
no contexto de uma imprensa contemporânea dita "de serviços" no género recensão crítica sobre o vinho e noutros textos jornalísticos, pretendendo dar conta do modo como é criada a ideia de prazer, a partir do vinho, nos textos estudados.

Tendo sido analisado o género recensão crítica sobre o vinho, na variante publicação especializada e variante publicação não especializada, verificou-se que o hedonismo é edificado pelo profissional jornalista especialista, que constrói uma representação qualificada de si e uma representação do seu interlocutor como o do consumidor que necessita da sua orientação para uma experiência bem-sucedida na área do vinho.

Em forma de balanço, é possível afirmar que o jornalista especialista da atividade de produção e de comercialização dos vinhos faz uso de estratégias linguísticas que revelam uma preferência pelo discurso interativo e pelo discurso teórico. Foram identificadas caraterísticas recorrentes de ordem enunciativa que configuram o tipo de discurso interativo, a saber, a presença de um sujeito produtor textual que se autodesigna na primeira pessoa (singular ou plural) e o reconhecimento de um interlocutor, também identificado através de formas verbais e pronominais de terceira pessoa (singular ou plural).

De um ponto de vista do estudo do agir, o jornalista fundamentou a autoridade da escrita na prática da experiência do vinho. Esse facto é bem evidente na recomendação de experiências na área do vinho, em construções com os verbos modais dever/poder+infinitivo (por exemplo, servir, acompanhar), claramente dirigidas a um interlocutor, o leitor.

É, então, de concluir, que o jornalista especialista funda a descrição da experiência do vinho na reflexão da sua prática profissional, apelando a experiências anteriormente vividas e textualmente retomadas, no âmbito da degustação do vinho, do conhecimento que possui da área ou quaisquer outros momentos que fundamentem observações sobre a atividade de produção e de comercialização do vinho. Nesse sentido, o jornalista constrói uma experiência do vinho com base no conhecimento vivido ou nas suas ações internas, mobilizados para induzir a experiência do vinho no leitor-consumidor. A esta capacidade atorial reflexiva equivale uma figuração interna do agir.

Correspondendo à mesma pessoa, desdobrada, textualmente, no leitor, e, comercialmente, no consumidor, a construção da representação do interlocutor é baseada em elementos heterorrepresentados, isto é, da responsabilidade do profissional - tais como a descrição da pouca fruição do vinho ou uma representação 
hierarquicamente dependente dos conselhos ou recomendações do especialista. $\mathrm{Na}$ medida em que a representação sobre outro sujeito não depende da sua vivência, a representação construída sobre o leitor corresponde a uma figuração externa do agir.

Efetivamente, ainda que outros textos jornalísticos apresentem uma mesma intenção de conduzir o leitor-consumidor à compra, verifica-se a ausência de uma autorrepresentação positiva do produtor textual e, consequentemente, de uma capacidade de orientar o mesmo leitor-consumidor.

\section{Anexo A: o corpus}

A - Recensão crítica enológica de publicação

a. publicação não especializada

\begin{tabular}{|c|c|c|c|c|}
\hline $\mathbf{N}^{\mathbf{0}}$ & Autor & Título & Publicação & Data \\
\hline T_01 & $\begin{array}{l}\text { Aníbal } \\
\text { Coutinho }\end{array}$ & "Estórias avinhadas" & Sol & 22.1 .2010 \\
\hline T_02 & $\begin{array}{l}\text { Aníbal } \\
\text { Coutinho }\end{array}$ & "Nus e mascarados" & Sol & 12.2.2010 \\
\hline T_03 & $\begin{array}{l}\text { Aníbal } \\
\text { Coutinho }\end{array}$ & "Amor de mãe" & Sol & 7.5.2010 \\
\hline T_04 & $\begin{array}{l}\text { Aníbal } \\
\text { Coutinho }\end{array}$ & "Vinho no feminino" & Sol & 7.7.2011 \\
\hline T_05 & $\begin{array}{l}\text { Edgardo } \\
\text { Pacheco }\end{array}$ & "Podridão tão boa" & Domingo & 25.7.2010 \\
\hline T_06 & $\begin{array}{l}\text { Edgardo } \\
\text { Pacheco }\end{array}$ & $\begin{array}{c}\text { "A melhor selecção } \\
\text { nacional" }\end{array}$ & Domingo & 30.8 .2010 \\
\hline T_07 & $\begin{array}{l}\text { Edgardo } \\
\text { Pacheco }\end{array}$ & "Para rodar no copo" & Domingo & 30.1 .2011 \\
\hline T_08 & $\begin{array}{l}\text { Edgardo } \\
\text { Pacheco }\end{array}$ & "Bom para comer" & Domingo & 27.2.2011 \\
\hline T_09 & $\begin{array}{l}\text { Edgardo } \\
\text { Pacheco }\end{array}$ & "Discrição francesa" & Domingo & 3.4 .2011 \\
\hline T_10 & $\begin{array}{l}\text { João Paulo } \\
\text { Martins }\end{array}$ & $\begin{array}{c}\text { "Portuguesa? Olhe que } \\
\text { não..." }\end{array}$ & Única & 1.11 .2008 \\
\hline T_11 & $\begin{array}{l}\text { João Paulo } \\
\text { Martins }\end{array}$ & $\begin{array}{c}\text { "Brancos da Primavera } \\
\text { já chegaram" }\end{array}$ & Única & 4.4.2009 \\
\hline T_12 & $\begin{array}{l}\text { João Paulo } \\
\text { Martins }\end{array}$ & $\begin{array}{c}\text { "Os campeões estão a } \\
\text { chegar" }\end{array}$ & Única & 16.5.2009 \\
\hline
\end{tabular}




\begin{tabular}{|c|c|c|c|c|}
\hline T_13 & $\begin{array}{l}\text { João Paulo } \\
\text { Martins }\end{array}$ & $\begin{array}{l}\text { "Vindimas vão } \\
\text { começar" }\end{array}$ & Única & 22.8.2009 \\
\hline T_14 & $\begin{array}{l}\text { Maria João de } \\
\text { Almeida }\end{array}$ & $\begin{array}{c}\text { "Fresco, diferente e } \\
\text { bom" }\end{array}$ & Única & 25.4 .2008 \\
\hline T_15 & $\begin{array}{l}\text { Maria João de } \\
\text { Almeida }\end{array}$ & "Um exemplo a seguir" & Única & 3.5 .2008 \\
\hline T_16 & $\begin{array}{l}\text { Maria João de } \\
\text { Almeida }\end{array}$ & $\begin{array}{c}\text { "Tinto com grande } \\
\text { classe" }\end{array}$ & Única & 21.6.2008 \\
\hline
\end{tabular}

publicação especializada

\begin{tabular}{|c|c|c|c|c|}
\hline $\mathbf{N}^{0}$ & Autor & Título & Publicação & Data \\
\hline GP_17 & - & $\begin{array}{l}\text { "Quinta Vale do } \\
\text { Bragão" }\end{array}$ & $\begin{array}{l}\text { Paixão pelo } \\
\text { Vinho, } \mathrm{n}^{\circ} 43\end{array}$ & 2011 \\
\hline GP_18 & Manuel Silva & "Arrepio doce" & $\begin{array}{l}\text { Paixão pelo } \\
\text { Vinho, } n^{\circ} 43\end{array}$ & 2011 \\
\hline T_19 & Manuel Silva & $\begin{array}{l}\text { "Alvarinhos - Porte } \\
\text { e ostentação" }\end{array}$ & $\begin{array}{l}\text { Paixão pelo } \\
\text { Vinho, } \mathrm{n}^{\circ} 45\end{array}$ & 2011 \\
\hline T_20 & $\begin{array}{l}\text { João Pereira } \\
\text { Santos }\end{array}$ & $\begin{array}{l}\text { "O Rosé tomou } \\
\text { conta da planície" }\end{array}$ & $\begin{array}{l}\text { Paixão pelo } \\
\text { Vinho, n }{ }^{\circ} 45\end{array}$ & 2011 \\
\hline T_21 & - & $\begin{array}{l}\text { "Um clássico } \\
\text { renovado" }\end{array}$ & $\begin{array}{c}\text { Revista de } \\
\text { Vinhos, } \mathrm{n}^{\circ} 256\end{array}$ & 2011 \\
\hline T_22 & João Afonso & $\begin{array}{c}\text { "Os Tourigas das } \\
\text { Servas" }\end{array}$ & $\begin{array}{c}\text { Revista de } \\
\text { Vinhos, } n^{\circ} 256\end{array}$ & 2011 \\
\hline T_23 & $\begin{array}{l}\text { João Paulo } \\
\text { Martins }\end{array}$ & $\begin{array}{c}\text { "O ataque do lobo } \\
\text { negro" }\end{array}$ & $\begin{array}{c}\text { Revista de } \\
\text { Vinhos, } \mathrm{n}^{\circ} 256\end{array}$ & 2011 \\
\hline T_24 & - & $\begin{array}{l}\text { "Douro com } \\
\text { frescura" }\end{array}$ & $\begin{array}{c}\text { Revista de } \\
\text { Vinhos, } n^{\circ} 260\end{array}$ & 2011 \\
\hline T_25 & $\begin{array}{l}\text { António } \\
\text { Falcão }\end{array}$ & $\begin{array}{l}\text { "O Pai Chão de Rui } \\
\text { Nabeiro" }\end{array}$ & $\begin{array}{c}\text { Revista de } \\
\text { Vinhos, } n^{\circ} 260\end{array}$ & 2011 \\
\hline T_26 & $\begin{array}{l}\text { António } \\
\text { Falcão e Luís } \\
\text { Antunes }\end{array}$ & $\begin{array}{l}\text { "Monte do Álamo } \\
\text { sobe a fasquia" }\end{array}$ & $\begin{array}{c}\text { Revista de } \\
\text { Vinhos, } n^{\circ} 260\end{array}$ & 2011 \\
\hline T_27 & $\begin{array}{l}\text { João Paulo } \\
\text { Martins, }\end{array}$ & $\begin{array}{c}\text { "Colheitas novas e } \\
\text { tardias" }\end{array}$ & $\begin{array}{c}\text { Revista de } \\
\text { Vinhos, } n^{\circ} 260\end{array}$ & 2011 \\
\hline T_28 & $\begin{array}{c}\text { João } \\
\text { Geirinhas e } \\
\text { Luís Lopes }\end{array}$ & $\begin{array}{l}\text { "Mochão (entre)abre } \\
\text { a arca dos tesouros" }\end{array}$ & $\begin{array}{l}\text { Revista de } \\
\text { Vinhos, } \\
\text { n }^{\circ} 260\end{array}$ & 2011 \\
\hline
\end{tabular}




\begin{tabular}{ccccc} 
T_29 & Rui Falcão & $\begin{array}{c}\text { "Vinhos velhos... e } \\
\text { épicos" }\end{array}$ & $\begin{array}{c}\text { Wine-A Essência } \\
\text { do Vinho, no 56 }\end{array}$ & 2011 \\
T_30 & Rui Falcão & $\begin{array}{c}\text { "Brilhantes } \\
\text { borbulhas" }\end{array}$ & $\begin{array}{c}\text { Wine-A Essência } \\
\text { do Vinho, n }{ }^{\circ} 59\end{array}$ & 2011 \\
\hline
\end{tabular}

B - Outros textos sobre o vinho

\begin{tabular}{|c|c|c|c|c|}
\hline $\mathbf{N}^{\mathbf{0}}$ & Autor & Título & Publicação & Data \\
\hline T_31 & $\begin{array}{l}\text { Fernando } \\
\text { Sobral }\end{array}$ & "Memórias do Douro" & Must & 12.2009 \\
\hline T_32 & $\begin{array}{l}\text { Fernando } \\
\text { Sobral }\end{array}$ & $\begin{array}{l}\text { "Aromas e sensações } \\
\text { chilenos" }\end{array}$ & Must & 12.2009 \\
\hline T_33 & $\begin{array}{l}\text { Fernando } \\
\text { Sobral }\end{array}$ & "No coração do Dão" & Must & 4.2010 \\
\hline T_34 & $\begin{array}{l}\text { Fernando } \\
\text { Sobral }\end{array}$ & "O misterioso M" & Must & 9.2010 \\
\hline T_35 & $\begin{array}{l}\text { Inês } \\
\text { Queiroz }\end{array}$ & $\begin{array}{l}\text { "Para acompanhar o } \\
\text { Verão" }\end{array}$ & Fora de Série & 3.7 .2010 \\
\hline T_36 & Ana Rajado & $\begin{array}{l}\text { "Graco, Herança } \\
\text { Romana, Fruto do } \\
\text { Alentejo" }\end{array}$ & $\mathrm{i}$ & 3.8 .2011 \\
\hline
\end{tabular}

\begin{abstract}
This work is carried out under Text Theory and Sociodiscursive Interactionism frameworks, and reports about how the domain of a discursive practice by the text producer is reflected in the text.

This view is exemplified by the analysis of a corpus of texts genres that combine the activity of the production and commercialization of wine with the journalistic activity, in particular, text genre critical review about wine. Since the set of texts observed falls within the so-called modern media "services" that participates in the hyperconsumption society and having as an analysis device the types of discourse, the analysis will be addressed to the representations that the specialist journalist builds on $\mathrm{him} /$ herself (figuration of the internal acting) and his/hers interlocutor, the consumer-reader (figuration of the external acting), later contrasted with other newspaper articles about wine. The data demonstrate that expert's knowledge about wine directly influences the hedonistic experience built in text, so that only the acting of this subject can mediate a qualified experience.
\end{abstract}

Keywords: Text theory. Sociodiscursive Interactionism. Acting. Expert. 


\section{Referências}

ADAM, Jean-Michel. Unités rédactionnelles et genres discursifs. Cadre general pour une approche de la presse écrite. Pratiques, Paris, n. 94, p. 3-18, 1997. Disponível em: <http://www.pratiques-cresef.com/p094_ad1.pdf $>$. Acessado em: 14 set. 2013.

ADAM, Jean-Michel. Entre le conseil et le consigne: les genres de l'incitation à l'action. Pratiques, n. 111-112, p. 7-37, 2001.

ADAM, Jean-Michel. Discours Procéduraux et autres Genres de l'Incitation à l'Action. Conclusion. In: Les Textes: types et prototypes. Séquences descriptives, narratives, argumentatives, explicatives, dialogales et genres de l'injonction-instruction. Paris: Armand Colin, 2011. p. 225-269.

ADAM, Jean-Michel; BONHOMME, Marc. L'Argumentation Publicitaire. Lassay-les-Châteaux: Armand Colin, 2007.

BAUDRILLARD, Jean. A Sociedade de Consumo. Colecção Arte e Comunicação, Edições 70, 2008.

BOTA, Cristian; BRONCKART, Jean-Paul. Volochinov et Bakhtine: Deux approches radicalement opposées de genres de textes et de leur statut. In Lynx, v. 26, 2007, p. 73-89.

BRONCKART, Jean-Paul. Atividade de linguagem, textos e discursos: por um interacionismo sócio-discursivo. São Paulo: Editora da PUC-SP, EDUC, 2003.

BRONCKART, Jean-Paul. Les genres de textes et leur contribution au développement psychologique. Langages, n. 153, Les genres de la parole, 2004, p. 98-108. Disponível em: <http://www.persee.fr/web/revues/home/prescript/ article/lgge_0458-e726X_2004_num_38_153_938>. Acesso em: 7 dez. 2013.

BRONCKART, Jean-Paul. La vie en questions : des textes aux langues, et retour. Conferência convidada. XXV ENCONTRO NACIONAL DA ASSOCIAÇÃO PORTUGUESA DE LINGUÍSTICA, 25. Textos Seleccionados, Porto: APL, 2009, p. 11-40.

BRONCKART, Jean-Paul. Les diferentes formes d'interaction et leur statut dans une science du langage: Réflexions et questions. Calidoscópio, v. 8, n. 2, p. 154-164, 2010. Disponível em: <http://www.revistas.unisinos.br/index.php/ calidoscopio/article/view/474/71>. Acesso em: 8 ago. 2013. 
BRONCKART, Jean-Paul; BULEA, Ecaterina. La dynamique de l'agir dans la dynamique langagiére. In: BARBIER, Jean-Marie; DURAND, Marc (Org.). Sujet, activité, environnement : approches, problèmes, outils. Paris: PUF, 2005. p. 105-134.

BULEA, Ecaterina; BRONCKART, Jean-Paul. Les représentations de l'agir enseignant dans le cadre du genre entretien. Raído, Dourados, v. 6, n. 11, p. 131149, 2012.

COUTINHO, Maria Antónia. Dos géneros de texto à gramática. D.E.L.T.A., v. 28, n. 1, p. 27-50, 2012. Disponível em: <http://www.scielo.br/pdf/delta/v28n1/ v28n1a02.pdf>. Acesso em: $10 \mathrm{dez} .2013$.

GROSSE, Ernst-Ulrich. Evolution et typologie des genres journalistiques. Essai d'une vue d'ensemble. In: ADAM, Jean-Michel; HERMAN, Thierry; LUGRIN, Gilles. Semen, n. 13. Genres de la presse écrite et analyse de discours. Paris: Presses Universitaires Franc-Comtoises, 2001. p. 15-36.

LIPOVETSKY, Gilles. A felicidade paradoxal: ensaio sobre a sociedade do hiperconsumo. Lisboa: Edições 70, 2007.

OLIVEIRA, Fátima. Tempo e Aspecto. In: MATEUS, Maria Helena Mira et al. Gramática da Língua Portuguesa. Lisboa: Caminho, 2003. cap. 6, p. 127-178.

PETERS, Tom. Reinventar o Mundo! Porto: Civilização Editora, 2008.

RASTIER, François. Arts et sciences du texte. Paris: P.U.F, 2001. Col. Formes Sémiotiques.

SANTOS, Carla Patrícia Rodrigues de Sousa Teixeira dos. A indução e a formulação de experiências. Análise linguística de textos da área do vinho. Tese (Doutorado em Linguística do Texto e do Discurso) - FCSH-UNL, Lisboa, 2014. Disponível em: < http://run.unl.pt/handle/10362/12319>.

VOLÓSHINOV, Valentin. El marxismo y la filosofía del lenguaje. Tradução de Tatiana Bubnova. Madrid: Alianza Editorial, 1992.

YON, Bernard. Estudo do Consumidor Português de Vinhos. Serviços de Edição da ESB/UCP: Orgal Impressores, 2003.

Submetido em: 31 de maio de 2015. Aceito para publicação em: 26 de outubro de 2015. 
Entrevista 
